\section{Tsix-mediated epigenetic switch of a CTCF-flanked region of the Xist promoter determines the Xist transcription program}

\author{
Pablo Navarro, Damian R. Page, Philip Avner, \\ and Claire Rougeulle ${ }^{1}$ \\ Unité de Génétique Moléculaire Murine, Institut Pasteur \\ 75724, Paris Cedex 15, France
}

Initiation of $\mathrm{X}$ inactivation depends on the coordinated expression of the sense/antisense pair Xist/Tsix. We show here that a precisely defined Xist promoter region flanked by CTCF is maintained by Tsix in a heterochromatic-like state in undifferentiated embryonic stem (ES) cells and shifts to a pseudoeuchromatic structure upon Tsix truncation. We further demonstrate that the epigenetic state of the Xist $5^{\prime}$ region prior to differentiation predicts the efficiency of transcriptional machinery recruitment to the Xist promoter during differentiation. Our results provide mechanistic insights into the Tsixmediated epigenetic regulation of Xist resulting in Xist promoter activation and initiation of $X$ inactivation in differentiating ES cells.

Supplemental material is available at http://www.genesdev.org.

Received March 30, 2006; revised version accepted August 17, 2006.

Histone modifications participate in the establishment of local chromatin structures that, in particular, render gene promoter permissive or not for the subsequent assembly and/or activation of the transcriptional machinery (Mellor 2005). Among such marks, covalent modifications of Lys 4, Lys 9, and Lys 27 of the histone H3 tail (H3K4, H3K9, and H3K27, respectively) are known to play crucial roles. H3K4 methylation and H3K9 acetylation have been extensively associated with active regions of the genome (euchromatin) while H3K9 and K27 methylation participate in the establishment and maintenance of silent domains (heterochromatin). The relationship between euchromatin and heterochromatin, dictated in part by covalent modifications of histones but also of CpG sites on DNA (Jaenisch and Bird 2003), provides an elegant support for the information required to establish heritable epigenetic states of gene expression programs during development (Turner 2002; Rasmussen 2003).

One of the most relevant paradigms for such epigenetic regulation is provided by $\mathrm{X}$ inactivation, in which

[Keywords: X inactivation; chromatin modifications; CTCF boundaries; noncoding RNA; antisense transcription; epigenetic regulation] ${ }^{1}$ Corresponding author.

E-MAIL rougeull@pasteur.fr; FAX 33-1-45-68-8656.

Article is online at http://www.genesdev.org/cgi/doi/10.1101/gad.389006. a single $\mathrm{X}$ chromosome is randomly chosen in females to be transcriptionally silenced at the onset of epiblast differentiation. Once established, this silent state is inherited through cell division and lineage commitment. Initiation of X inactivation depends on the noncoding Xist RNA, which coats the X chromosome in cis and induces gene silencing and heterochromatin formation (Heard 2005). The regulation of Xist expression is therefore an essential event of the $\mathrm{X}$-inactivation process, thought to involve both post-transcriptional (Panning et al. 1997; Sheardown et al. 1997; Ciaudo et al. 2006) and transcriptional (Navarro et al. 2005; Sun et al. 2006) mechanisms.

Embryonic stem (ES) cells recapitulate random $\mathrm{X}$ inactivation at the onset of cell differentiation and have proved an excellent model for the study of this epigenetic process (Chaumeil et al. 2002). In undifferentiated female ES cells, both X chromosomes transcribe low levels of Xist RNA. As the cell differentiates, one Xist allele per diploid set of autosomes is up-regulated, inducing $X$ inactivation in cis, while the second Xist allele of females and the single Xist allele of males are turned off. An intriguing characteristic of the Xist gene is its complete overlapping by a noncoding antisense transcription unit, Tsix, which represses Xist RNA accumulation in cis (Ogawa and Lee 2002; Rougeulle and Avner 2004). Studies of Tsix mutations in both female (Debrand et al. 1999; Lee and Lu 1999; Luikenhuis et al. 2001) and male (Morey et al. 2004; Vigneau et al. 2006) ES cells indicate that an $\mathrm{X}$ chromosome in which Tsix transcription has been disrupted systematically up-regulates Xist expression at the onset of ES cell differentiation, whether in male or female ES cells. This indicates that Tsix ensures the randomness of Xist up-regulation in females and programs Xist for silencing in males. In agreement with this, insertion of an inducible promoter to force Tsix expression during female ES cell differentiation abolishes the possibility of the mutated allele to up-regulate Xist (Stavropoulos et al. 2001). Tsix therefore determines the potential of Xist to be up-regulated at the onset of differentiation.

Recently, we and others have shown that Tsix has complex chromatin remodeling activities within the Xist/Tsix locus. Tsix triggers H3K4 dimethylation within the overall locus but represses increased accumulation across the Xist promoter (Navarro et al. 2005). In addition, male mouse embryonic fibroblasts (MEFs, which in contrast to females do not express Xist) derived from Tsix mutants show aberrant chromatin conformation at the Xist promoter, characterized in particular by high levels of H3K4 dimethylation (Sado et al. 2005).

Given (1) the dramatic effect that Tsix abolishment has both on Xist chromatin modification and expression levels and (2) the involvement of chromatin conformation in the establishment and maintenance of specific gene expression programs during differentiation, we hypothesized that Tsix regulation may induce different epigenetic states at the Xist promoter on the future inactive and active $\mathrm{X}$ chromosomes to determine Xist expression programs. Our analysis exploiting wild-type and Tsixtruncated ES cells demonstrates that Tsix represses the euchromatinization of a CTCF-flanked region of the Xist promoter, precluding transcriptional Xist up-regulation during differentiation. In contrast, Tsix truncation gen- 
erates a stable pseudoeuchromatic state at the Xist $5^{\prime}$ region that preempts transcription apparatus assembly at the Xist promoter and initiation of X inactivation. These conclusions are in striking contrast to those of a recent study (Sun et al. 2006), where it was suggested that down-regulation of Tsix induces a heterochromatic state at Xist, paradoxically followed by transcriptional activation of Xist.

\section{Results and Discussion}

Tsix triggers H3K9 trimethylation and DNA methylation to the Xist $5^{\prime}$ region

Antisense transcription across the Xist promoter was previously shown to repress increased levels of H3K4 dimethylation around this specific region (Navarro et al. 2005). In order to map precisely the region affected and to assess whether other epigenetic marks are similarly controlled by Tsix, we have undertaken a systematic analysis of the Xist promoter region (Fig. 1A) in wild-type and mutant male ES cells in which Tsix transcription is ec-

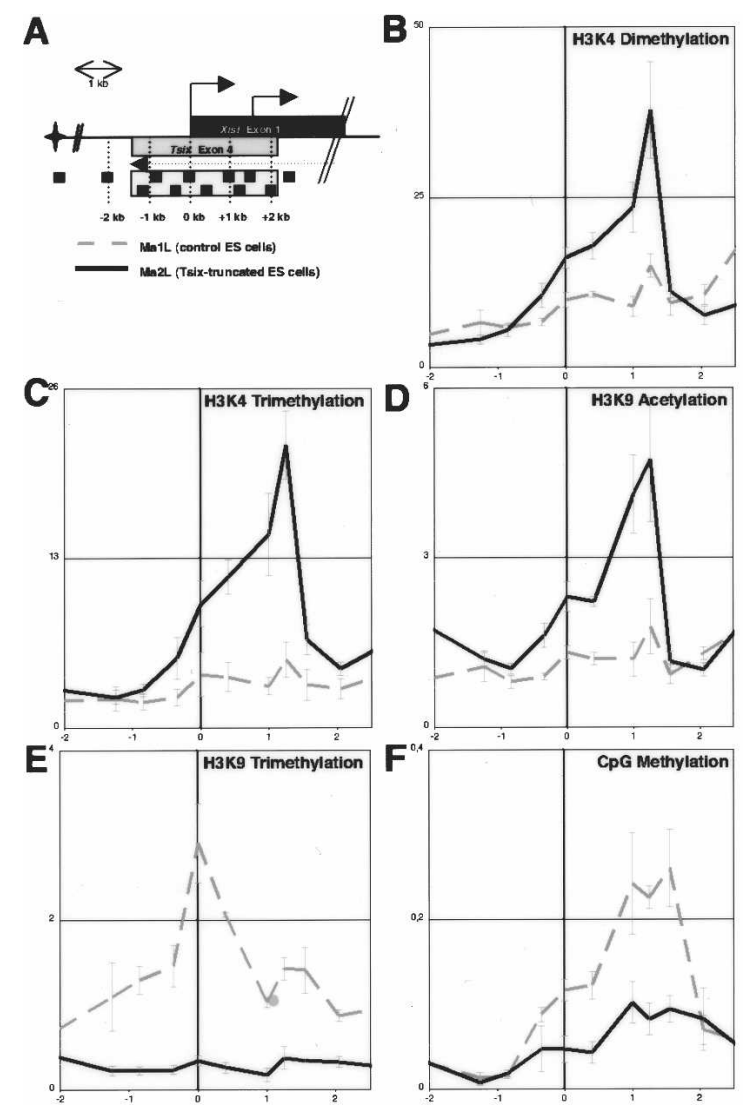

Figure 1. Tsix-mediated chromatin remodeling of the Xist $5^{\prime}$ region. (A) Schematic representation of Xist $5^{\prime}$ region, with the primer pairs used. Exon 1 of Xist and exon 4 of Tsix are represented by dark and light boxes, respectively. $(B-F)$ ChIP analysis of H3K4 dimethylation $(B), \mathrm{H} 3 \mathrm{~K} 4$ trimethylation $(C), \mathrm{H} 3 \mathrm{~K} 9$ acetylation $(D), \mathrm{H} 3 \mathrm{~K} 9$ trimethylation $(E)$, and CpG methylation $(F)$ in wild-type (dotted line) and Tsix-truncated (plain line) male ES cells. For each panel, the average percent immunoprecipitation calculated for each position is plotted against the genomic location (kilobases) with respect to the Xist transcriptional initiation site (vertical bold line). Each graph shows the average percent immunoprecipitation obtained using two to three independent chromatin extracts. topically terminated before it overlaps the Xist transcription unit (Luikenhuis et al. 2001). We show that Tsix truncation leads to a consistent increase in $\mathrm{H} 3 \mathrm{~K} 4$ dimethylation specifically in the -1 - to $+1.5-\mathrm{kb}$ region spanning the Xist promoter (Fig. 1B). Importantly, this effect is not restricted to $\mathrm{H} 3 \mathrm{~K} 4$ dimethylation but is also observed for other active histone modifications since this region, devoid of $\mathrm{H} 3 \mathrm{~K} 4$ trimethylation and $\mathrm{H} 3 \mathrm{~K} 9$ acetylation in wild-type ES cells (Fig. 1C,D; Supplementary Fig. 1B), is highly enriched for both marks upon truncation of Tsix (Fig. 1C,D). This clearly demonstrates that Tsix transcription across the Xist promoter represses the accumulation of active histone marks within the -1 - to $+1.5-\mathrm{kb}$ interval in undifferentiated ES cells. The maximum of active histone marks enrichment corresponds to positions $1 \mathrm{~kb}$ downstream from the Xist P1 promoter. This could be linked to the presence of a control element at this position and may explain why the recent analysis of a single position just $5^{\prime}$ of $\mathrm{P} 1$ failed to detect such an enrichment (Sun et al. 2006).

Strikingly, the gain of the three active marks tested in the mutant was accompanied by the virtually complete loss of H3K9 trimethylation around the Xist 5' region (Fig. 1E). Importantly, this effect is not restricted to histone methylation since DNA methylation, known to partially mark the Xist promoter in ES cells (Sado et al. 1996), was also lost after Tsix truncation (Fig. 1F).

Our results indicate that, in ES cells, Tsix blocks the euchromatinization of the Xist $5^{\prime}$ region by triggering negative epigenetic marks, possibly through a mechanism similar to that used by Xist RNA to induce Xchromosome-wide heterochromatinization (Bernstein and Allis 2005), involving the recruitment of repressive enzymatic complexes to the Xist $5^{\prime}$ region (such as H3K9 and DNA methyltransferases together with histone deacetylases and/or H3K4 demethylases). The recent finding of biochemical interaction between Dnmt3a, a de novo DNA methyltransferase, and Tsix RNA (Sun et al. 2006) supports this idea.

\section{Global euchromatic effects of Tsix transcription on chromatin conformation of the Xist/Tsix locus}

In the overall Xist/Tsix locus, the effect of Tsix on H3K4 dimethylation was shown to be distinct from its effect at the Xist promoter (Navarro et al. 2005). It was tempting to speculate that similar regulation would apply to the other modifications controlled by Tsix within the Xist $5^{\prime}$ region. To address this specific issue, additional positions upstream of and downstream from the inserted transcriptional stop signal were analyzed by chromatin immunoprecipitation (ChIP) (Fig. 2A). The levels of H3K4 trimethylation (Fig. 2C) and H3K9 acetylation (Fig. 2D) are substantially reduced in the mutant within the first few kilobases immediately downstream from the transcriptional stop site. Within Xist itself (Fig. 2, primers c, d, and e), however, the levels of these two modifications are found, in both wild-type and mutant ES cells, to be as low as the levels seen within the hotspot of H3K9 and K27 methylation located 5' to Xist (Fig. 2, primers a and b; Heard et al. 2001; Rougeulle et al. 2004), a region known to be devoid of euchromatic marks.

In addition, the high levels of H3K9 trimethylation that are detected across the overall Xist/Tsix locus with the exception of the Tsix promoter (Fig. 2E; Supplemen- 
A
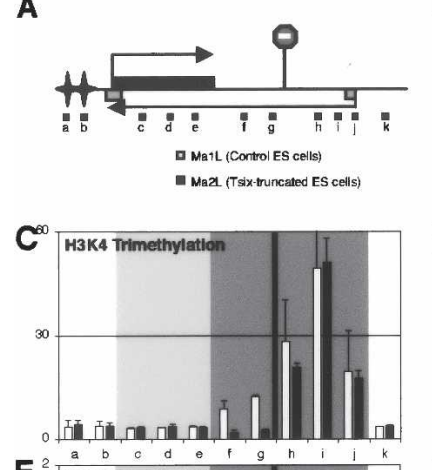

$E^{2} \frac{a}{\text { H3K9 Trimethylation }}$

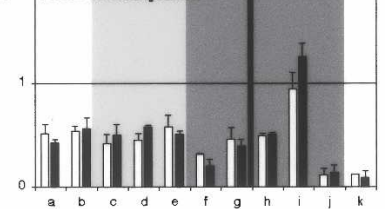

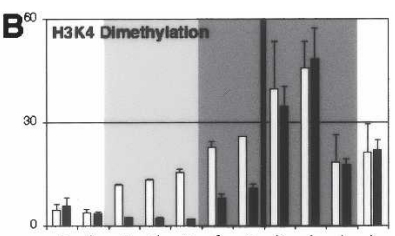
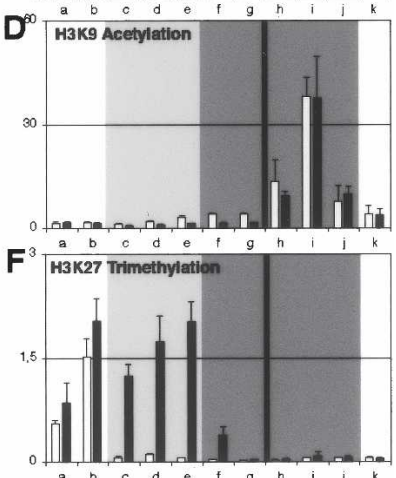

Figure 2. Tsix-mediated chromatin remodeling of the Xist/Tsix locus. (A) Schematic representation of the Xist/Tsix locus. The stop signal marks the location of the inserted transcriptional stop sequence in the Tsix-truncated (Ma2L) male ES cell line. The stars represent the hotspot of $\mathrm{H} 3 \mathrm{~K} 9$ and $\mathrm{K} 27$ methylation, which covers a 350-kb region 5' to Xist (Rougeulle et al. 2004). The positions of the primers used in the ChIP analysis $(\mathrm{a}-\mathrm{k})$ are indicated (none of them correspond to those described in Fig. 1). $(B-F)$ ChIP analysis of H3K4 dimethylation $(B), \mathrm{H} 3 \mathrm{~K} 4$ trimethylation $(C), \mathrm{H} 3 \mathrm{~K} 9$ acetylation $(D)$, H3K9 trimethylation $(E)$, and H3K27 trimethylation $(F)$ in wild-type (white bars) and Tsix-truncated (black bars) male ES cells. The darkgray portions of the graphs correspond to positions transcribed in Tsix orientation only, while the light-gray parts correspond to position transcribed in both Xist and Tsix orientations. The vertical bar indicates the position of stop signal in the Tsix-truncated cell line.

tary Fig. 1E), which are reminiscent of what has been recently described for other actively transcribed genes (Vakoc et al. 2005), were found unaffected in the Tsixtruncated mutant. Similarly, H3K9 dimethylation levels remain identical in wild-type and Tsix mutant cells (data not shown).

We conclude that among the histone marks analyzed, H3K4 dimethylation (Fig. 2B) is the only modification triggered by Tsix along the overall Tsix transcription unit, from its $5^{\prime}$ to $3^{\prime}$ ends. In addition, Tsix blocks the enrichment for H3K27 trimethylation (Fig. 2F), similarly to what was recently reported in an independent Tsix mutant (Sun et al. 2006). A detailed analysis of the histone modifications in the Tsix $3^{\prime}$ and $5^{\prime}$ ends in wild-type female ES cells supports these interpretations (Supplementary Fig. 1).

\section{CTCF as a candidate protein to constrain} the repressive epigenetic effects mediated by Tsix to the Xist 5' region exclusively

We have demonstrated that Tsix oppositely affects the Xist $5^{\prime}$ region and the overall Tsix transcription unit. This suggests that an insulation of the Xist 5' region, capable of limiting the spreading of H3K9 trimethylation and/or CpG methylation to the overall Xist/Tsix region, may be occurring. Importantly, the region showing variation of chromatin modification levels appears to be precisely defined and restricted to the -1 - to +1.5 -kb interval of the Xist promoter region (Fig. 3A).

In mammals, CTCF has been shown to be able to in-

sulate specific regions of the genome and to define distinct chromatin domains. CTCF binds to regions of transition between $\mathrm{X}$-inactivated genes and genes escaping $\mathrm{X}$ inactivation (Filippova et al. 2005) and acts at the CTG repeats of the DM1 locus to constrain $\mathrm{H} 3 \mathrm{~K} 9$ methylation and prevent its spreading (Cho et al. 2005). Like the CTG repeats at the DM1 locus, the Xist 5' region can be viewed as an island of negative epigenetic marks embedded within a region of euchromatin-associated histone modifications. We therefore searched for CTCF binding on both sides of the $-1-$ to $+1.5-\mathrm{kb}$ interval. Using two independent antibodies against CTCF (Supplementary Fig. 2A,B), we were able to immunoprecipitate CTCF at the predicted positions in both undifferentiated female (Fig. 3B) and male ES cells (Fig. 3C, dotted line).

The binding profile of CTCF was found to be altered in Tsix-truncated cells (Fig. 3C, plain line). In all chromatin preparations analyzed, the binding over site cl was systematically noted to be higher in mutant than in wildtype cells. Although more variability was observed in CTCF binding at the $\mathrm{c} 2$ site, higher levels in the mutant than in the wild-type were never observed. Interestingly, the modification of CTCF-binding profile occurring upon truncation of Tsix leads to a profile similar to that of female MEFs, in which Tsix is transcriptionally si-

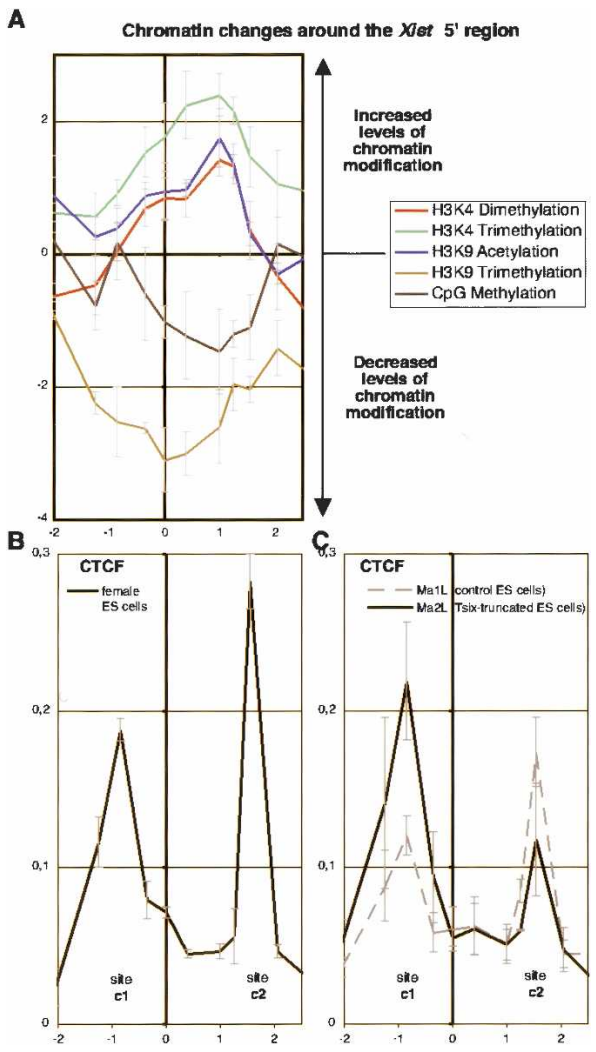

Figure 3. CTCF binding to the Xist $5^{\prime}$ region. $(A)$ The graph shows the ratio between Tsix-truncated (Ma2L) and wild-type (Ma1L) obtained for each epigenetic modification analyzed in Figure 1. Note that ratios are plotted in a $\log _{2}$ scale against the genomic position according to the Xist transcriptional start site. $(B)$ Analysis of CTCF binding across the Xist $5^{\prime}$ region in female ES cells. The graph shows the average percent immunoprecipitation $(n=2)$ calculated for each position. (C) Similar analysis of CTCF binding in wild-type (MalL, dotted lines) and Tsix-truncated (Ma2L, plain lines) male ES cells ( $n=3$ for both cell lines). 
lenced (cf. the plain line in Fig. 3C and Supplementary Fig. 2C). Based on these results, we propose that CTCF defines the boundaries of chromatin domains differentially regulated by $T$ six.

Tsix truncation leads to inappropriate transcriptional up-regulation of Xist in differentiated male ES cells

In undifferentiated ES cells, Xist expression is significantly down-regulated through repression of the transcription machinery assembly at the Xist P1 promoter (Navarro et al. 2005). This correlates with the finding that Tsix induces, across this specific region, the accumulation of epigenetic marks associated with inactive chromatin and represses the enrichment for active histone modifications. The truncation of Tsix, which completely remodels the chromatin architecture of the CTCF-flanked Xist 5' region (Fig. 1) has, however, been shown to have no direct influence on the efficiency of transcription preinitiation complex (PIC) recruitment to the Xist P1 promoter in undifferentiated cells (Navarro et al. 2005). One possible explanation could be that the simultaneous enrichment at the Xist promoter for both H3K27 trimethylation (Sun et al. 2006; P. Navarro C. Chureau, S. Vigneau, P. Avner, P. Clerc, and C. Rougelle, in prep.) and euchromatin-associated marks resulting from Tsix mutation generates a bivalent structure reminiscent to that described at other noncoding loci, which represses expression in ES cells but poises it for activation on differentiation (Bernstein et al. 2006). The recent finding of ectopic Xist RNA accumulation and X inactivation in differentiated Tsix mutant male ES cells (Vigneau et al. 2006) suggests that, upon truncation of Tsix, the Xist promoter is indeed primed to undergo transcriptional up-regulation.

To test this hypothesis, wild-type and mutant male ES cells were induced to differentiate and levels of RNA Polymerase II and TFIIB (Fig. 4A) measured at several different promoters. As expected, in both wild-type and mutant cells, PIC recruitment to the Oct3/4 promoter was repressed after $4 \mathrm{~d}$ of retinoic acid treatment, while only minor variations were observed at the $\beta$-actin and ArpoPO promoters. The down-regulation of Tsix that takes place during differentiation (Lee et al. 1999) appears to be regulated at the level of PIC recruitment, as an $80 \%$ reduction in RNA Polymerase II and TFIIB binding at the Tsix promoter was observed in both wild-type and mutant cells after $4 \mathrm{~d}$ of differentiation. In wild-type cells, the levels of PIC recruitment to Xist P1 promoter were either unchanged (TFIIB) or slightly reduced (RNA Polymerase II).

In striking contrast, RNA Polymerase II and TFIIB binding to P1 were significantly increased after $4 \mathrm{~d}$ of differentiation in Tsix-truncated cells (Fig. 4A). At P2, however, the second Xist promoter located $1.5 \mathrm{~kb}$ downstream from P1, no change in PIC binding was observed, confirming that only $\mathrm{P} 1$ is developmentally regulated (Navarro et al. 2005) This elevation in PIC recruitment to the Xist P1 promoter leads to significant differences in $X$ ist transcription levels as evaluated both by RNA Polymerase II distribution within the Xist first kilobases (from position 0.5 to 2.5) (Fig. 4B) and by levels of primary unspliced Xist transcript measured using quantitative intronic RT-PCR (Fig. 4C). These results demonstrate that Xist transcription is clearly up-regulated in differentiating Tsix mutant male ES cells, and this

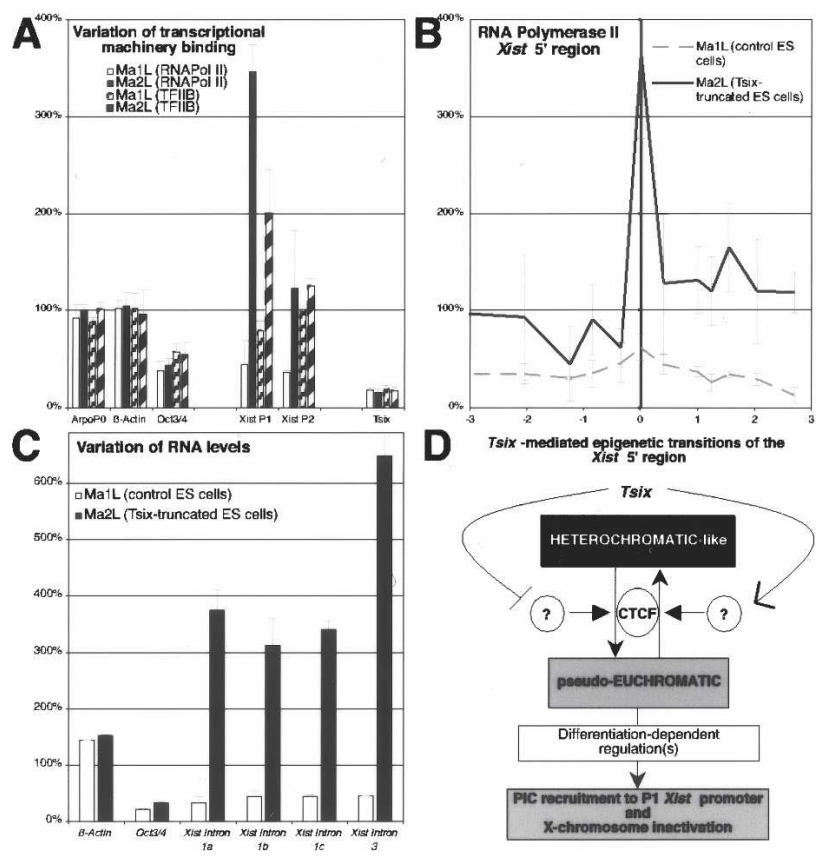

Figure 4. Analysis of PIC recruitment to Xist promoter in differentiating Tsix-truncated male ES cells. (A) Analysis of RNA Polymerase $(n=2)$ and TFIIB $(n=2)$ binding at the two Xist promoters (P1 and P2), the Tsix promoter, and three control promoters (ArpoPO, $\beta$-Actin, and Oct3/4) after $4 \mathrm{~d}$ of differentiation of wild-type (white bars) and mutant (black bars) male ES cells. (B) Extensive analysis across the Xist $5^{\prime}$ region of RNA Polymerase II distribution after $4 \mathrm{~d}$ of differentiation in control (dotted lines) and Tsix-truncated (black lines) male ES cells. For $A$ and $B$, the graph shows the fold variation in binding calculated by dividing the percent immunoprecipitation obtained at day 4 by the percent immunoprecipitation obtained at day 0 . Ratios $>100 \%$ indicate an increase in binding, and ratios $<100 \%$ indicate a release of the analyzed factor. (C) Analysis of RNA levels in wild-type (white bars) and Tsix-truncated (black bars) male ES cells differentiated for $4 \mathrm{~d}$. Spliced RNA for $\beta$-Actin and Oct $3 / 4$ are shown as controls. Four independent primer pairs (Xist intron la, $1 \mathrm{~b}$, and $1 \mathrm{c}$ and Xist intron 3 ) were used to evaluate the fold variation of primary, unspliced Xist RNA levels in Tsix-truncated ES cells. Note that in wild-type ES cells, the four primers mapping within Xist introns also amplify Tsix RNA. The ratios between day 4 and day 0 of differentiation were calculated after standardizing each amplification against Arpo PO mRNA levels. (D) A model for the role of Tsix in programming Xist transcription. The chromatin structure of the Xist 5' region is controlled by Tsix. Continuous transcription of Tsix in undifferentiated ES cells maintains the region in a heterochromatic-like structure (characterized by H3K9 trimethylation and CpG methylation, black box). In the absence of Tsix, the region adopts a pseudoeuchromatic structure (characterized by H3K4 di/ trimethylation and H3K9 acetylation, gray box). CTCF likely participates in the definition of the region submitted to such a Tsixdependent transition. Depending on these chromatic states, the Xist promoter will be differentially regulated during differentiation. When a euchromatic conformation is acquired early enough during (or before) differentiation, the Xist P1 promoter will recruit the transcriptional machinery to produce high levels of Xist RNA and therefore induce $\mathrm{X}$ inactivation, whether in female or male ES cells. In contrast, when silent epigenetic marks characterize the Xist $5^{\prime}$ region exclusively, the Xist promoter is unable to efficiently recruit the transcriptional machinery, preventing Xist up-regulation and $\mathrm{X}$ inactivation.

correlates with ectopic X inactivation (Vigneau et al. 2006).

\section{Conclusions}

We demonstrate here that Tsix induces a number of epigenetic marks within the Xist/Tsix region, which result 
in a CTCF-flanked Xist 5' region enriched for H3K9 trimethylation and DNA methylation, embedded within a larger euchromatic domain enriched for H3K4 dimethylation and protected from H3K27 trimethylation. Under these conditions, male ES cells are unable to transcriptionally up-regulate the Xist promoter at the onset of differentiation. In contrast, Tsix truncation leads to elevated $\mathrm{H} 3 \mathrm{~K} 4 \mathrm{di} /$ trimethylation and $\mathrm{H} 3 \mathrm{~K} 9$ acetylation at the Xist 5' region prior to cell differentiation. Strikingly, under this primed state for activation, Tsix-truncated male ES cells efficiently up-regulate Xist transcription through stimulation of PIC recruitment to the Xist P1 promoter during differentiation, with concomitant ectopic X inactivation (Vigneau et al. 2006). It therefore appears that the chromatin modifications induced by Tsix over the Xist promoter are sufficient to determine the transcriptional fate of Xist at the onset of cell differentiation. We conclude that Tsix mediates the counting process of $\mathrm{X}$ inactivation, which precludes high Xist upregulation in males, through the epigenetic repression of the Xist promoter.

This study has further consequences for our understanding of X-inactivation regulation in female ES cells, where Tsix is repressed first on the future inactive $\mathrm{X}$ (Lee et al. 1999). In this context, the initial monoallelic Tsix repression in a specific time window of differentiation will induce the establishment of a euchromatic architecture at a single Xist promoter region, allowing monoallelic PIC recruitment and participating to monoallelic Xist RNA up-regulation and $\mathrm{X}$ inactivation. We propose that asymmetric Tsix silencing, which might be regulated through the activity of Tsix control regions (Stavropoulos et al. 2005), achieves choice through the epigenetic activation of a single Xist promoter. On the second $X i s t$ promoter in female and on the single $\mathrm{X}$ in male cells, the repressive chromatin conformation, initially maintained by continuous transcription of Tsix, is subsequently propagated by Tsix-independent mechanisms. This is supported by the fact that in male MEFs, the inactive Xist promoter is devoid of active histone marks although Tsix is silenced (Supplementary Fig. 3).

Our findings demonstrate a crucial role for Tsix in programming the Xist expression pattern through modifications of chromatin structure of a precise CTCF-flanked Xist 5 ' region. These results illustrate the extraordinary epigenetic potential of noncoding antisense transcription units, whose number in the genome is surprisingly higher than previously thought (Kiyosawa et al. 2003; Numata et al. 2003). Interestingly, recruitment of repressive histone marks by an antisense RNA has also been suggested to occur in the imprinted cluster on mouse chromosome 7 (Lewis et al. 2004; Umlauf et al. 2004). Whether other antisense transcription units epigenetically control the expression of their sense counterpart through histone and DNA modifications will be key to our understanding of the epigenome regulation.

\section{Materials and methods}

\section{Cell culture}

Cells were cultured and differentiated as previously described (Navarro et al. 2005; Vigneau et al. 2006). Chromatin and RNA of undifferentiated and differentiated Ma1L and Ma2L cell lines were prepared and analyzed in parallel.

ChIP

ChIP assays were performed as described (Navarro et al. 2005) with the exception of sonication, which was performed using a Bioruptor (Di- agenode) according to the manufacturer's instructions. Ten micrograms to $20 \mu \mathrm{g}$ of chromatin were used for each immunoprecipitation. The following antibodies were used at the indicated dilutions: TFIIB (1/50; Santa Cruz Biotechnology), CTCF (1/50; Santa Cruz Biotechnology), RNAPolII (1/500; Euromedex), H3 di-meK4 (1/100; Upstate Biotechnology), tri-meK9 (1/100; Upstate Biotechnology), tri-meK27 (1/500; Upstate Biotechnology), and tri-meK4 (1/250; Abcam).

Methyl-CpG DNA immunoprecipitation (MeDIP)

MeDIP assay was performed as described (Weber et al. 2005). Briefly, genomic DNA from unfixed cells was fragmented by sonication, and $4 \mu \mathrm{g}$ of denatured DNA were incubated with $10 \mu \mathrm{L}$ of monoclonal antibody against 5-methylcytidine (Eurogentec) in MeDIP buffer (10 mM Na-phosphate at $\mathrm{pH} 7,0.14 \mathrm{M} \mathrm{NaCl}, 0.05 \%$ Triton X-100) for $2 \mathrm{~h}$ with overhead shaking at $4^{\circ} \mathrm{C}$. Immunocomplexes were recovered using protein G-Sepharose beads (Sigma) and washed three times with $1 \mathrm{~mL}$ of MeDIP buffer. The immunoprecipitated DNA was eluted in $250 \mu \mathrm{L}$ elution buffer (50 mM TrisHCl at $\mathrm{pH} \mathrm{8,} 10 \mathrm{mM}$ EDTA, 1\% SDS) for $15 \mathrm{~min}$ at $65^{\circ} \mathrm{C}$. After proteinase $\mathrm{K}$ (Eurobio) treatment, the immunoprecipitated DNA was phenol/chloroform-extracted and ethanol-precipitated. DNA pellets were resuspended in $60 \mu \mathrm{L}$ of $\mathrm{H}_{2} \mathrm{O}$ and $5 \mu \mathrm{L}$ were used for realtime PCR quantification

Real-time PCR analysis of ChIP and MeDIP assays

The immunoprecipitated DNA and a $1 / 100$ dilution of the input DNA were analyzed by real-time PCR using SYBR Green Universal Mix and an ABI Prism 7700 (Perkin-Elmer Applied Biosystems) as previously described (Navarro et al. 2005).

Quantitative RT-PCR

Random-primed RT was performed at $42^{\circ} \mathrm{C}$ with SuperScript II reverse transcriptase (Invitrogen) using $4 \mu \mathrm{g}$ of DNAse-treated (Roche) RNA isolated from cell cultures with RNable (Eurobio). Control reactions lacking enzyme were verified negative. We used Arpo P0 transcript levels to normalize between samples. All the primer sequences are provided as Supplementary Figure 4.

\section{Acknowledgments}

We thank Ken Zaret and Marc Lalande for critical reading of the manuscript, Dirk Schübeler for the MeDIP protocol, and Dmitry Loukinov and Victor Lobanenkov for the kind gift of anti-CTCF 9-Mabs mix. This work was supported by the Epigenome Network of Excellence, the French Ministry of Research under the Action Concertée Incitative (contract no. 032526), and the Agence Nationale pour la Recherche (ANR, contract no. 05-JCJC-0166-01). C.R and P.A are supported by the CNRS. D.R.P. was supported by successive fellowships from the European Molecular Biology Organization (ALTF 550-2004) and the Swiss National Science Foundation (PBZHA-108411).

\section{References}

Bernstein, E. and Allis, C.D. 2005. RNA meets chromatin. Genes \& Dev. 19: 1635-1655.

Bernstein, B.E., Mikkelsen, T.S., Xie, X., Kamal, M., Huebert, D.J., Cuff, J., Fry, B., Meissner, A., Wernig, M., Plath, K., et al. 2006. A bivalent chromatin structure marks key developmental genes in embryonic stem cells. Cell 125: 315-326.

Chaumeil, J., Okamoto, I., Guggiari, M., and Heard, E. 2002. Integrated kinetics of $\mathrm{X}$ chromosome inactivation in differentiating embryonic stem cells. Cytogenet. Cell Genet. 99: 75-84.

Cho, D.H., Thienes, C.P., Mahoney, S.E., Analau, E., Filippova, G.N., and Tapscott, S.J. 2005. Antisense transcription and heterochromatin at the DM1 CTG repeats are constrained by CTCF. Mol. Cell 20: $483-$ 489.

Ciaudo, C., Bourdet, A., Cohen-Tannoudji, M., Dietz, H.C., Rougeulle, C., and Avner, P. 2006. Nuclear mRNA degradation pathway(s) are implicated in Xist regulation and $\mathrm{X}$ chromosome inactivation. PLOS Genet. 2: e94.

Debrand, E., Chureau, C., Arnaud, D., Avner, P., and Heard, E. 1999. Functional analysis of the DXPas34 locus, a 3' regulator of Xist expression. Mol. Cell. Biol. 19: 8513-8525. 
Filippova, G.N., Cheng, M.K., Moore, J.M., Truong, J.P., Hu, Y.J., Nguyen, D.K., Tsuchiya, K.D., and Disteche, C.M. 2005. Boundaries between chromosomal domains of $\mathrm{X}$ inactivation and escape bind CTCF and lack CpG methylation during early development. Dev. Cell 8: $31-42$.

Heard, E. 2005. Delving into the diversity of facultative heterochromatin: The epigenetics of the inactive X chromosome. Curr. Opin. Genet. Dev. 15: 482-489.

Heard, E., Rougeulle, C., Arnaud, D., Avner, P., Allis, C.D., and Spector, D.L. 2001. Methylation of histone H3 at Lys-9 is an early mark on the $\mathrm{X}$ chromosome during $\mathrm{X}$ inactivation. Cell 107: 727-738.

Jaenisch, R. and Bird, A. 2003. Epigenetic regulation of gene expression: How the genome integrates intrinsic and environmental signals. Nat. Genet. (Suppl.) 33: 245-254.

Kiyosawa, H., Yamanaka, I., Osato, N., Kondo, S., and Hayashizaki, Y. 2003. Antisense transcripts with FANTOM2 clone set and their implications for gene regulation. Genome Res. 13: 1324-1334.

Lee, J.T. and Lu, N. 1999. Targeted mutagenesis of Tsix leads to nonrandom X inactivation. Cell 99: 47-57.

Lee, J.T., Davidow, L.S., and Warshawsky, D. 1999. Tsix, a gene antisense to Xist at the X-inactivation centre. Nat. Genet. 21: 400-404.

Lewis, A., Mitsuya, K., Umlauf, D., Smith, P., Dean, W., Walter, J., Higgins, M., Feil, R., and Reik, W. 2004. Imprinting on distal chromosome 7 in the placenta involves repressive histone methylation independent of DNA methylation. Nat. Genet. 36: 1291-1295.

Luikenhuis, S., Wutz, A., and Jaenisch, R. 2001. Antisense transcription through the Xist locus mediates Tsix function in embryonic stem cells. Mol. Cell. Biol. 21: 8512-8520.

Mellor, J. 2005. The dynamics of chromatin remodeling at promoters. Mol. Cell 19: 147-157.

Morey, C., Navarro, P., Debrand, E., Avner, P., Rougeulle, C., and Clerc, P. 2004. The region $3^{\prime}$ to Xist mediates X chromosome counting and H3 Lys-4 dimethylation within the Xist gene. EMBO J. 23: 594-604.

Navarro, P., Pichard, S., Ciaudo, C., Avner, P., and Rougeulle, C. 2005. Tsix transcription across the Xist gene alters chromatin conformation without affecting $X$ ist transcription: Implications for X-chromosome inactivation. Genes \& Dev. 19: 1474-1484.

Numata, K., Kanai, A., Saito, R., Kondo, S., Adachi, J., Wilming, L.G., Hume, D.A., RIKEN GER Group, GSL Members, Hayashizaki, Y., et al. 2003. Identification of putative noncoding RNAs among the RIKEN mouse full-length cDNA collection. Genome Res. 13: 13011306.

Ogawa, Y. and Lee, J.T. 2002. Antisense regulation in X inactivation and autosomal imprinting. Cytogenet. Genome Res. 99: 59-65.

Panning, B., Dausman, J., and Jaenisch, R. 1997. X chromosome inactivation is mediated by Xist RNA stabilization. Cell 90: 907-916.

Rasmussen, T.P. 2003. Embryonic stem cell differentiation: A chromatin perspective. Reprod. Biol. Endocrinol. 1: 100

Rougeulle, C. and Avner, P. 2004. The role of antisense transcription in the regulation of X-inactivation. Curr. Top. Dev. Biol. 63: 61-89.

Rougeulle, C., Chaumeil, J., Sarma, K., Allis, C.D., Reinberg, D., Avner, P., and Heard, E. 2004. Differential histone H3 Lys-9 and Lys-27 methylation profiles on the X chromosome. Mol. Cell. Biol. 24: 5475 5484.

Sado, T., Tada, T., and Takagi, N. 1996. Mosaic methylation of Xist gene before chromosome inactivation in undifferentiated female mouse embryonic stem and embryonic germ cells. Dev. Dyn. 205: 421-434

Sado, T., Hoki, Y., and Sasaki, H. 2005. Tsix silences Xist through modification of chromatin structure. Dev. Cell 9: 159-165.

Sheardown, S.A., Duthie, S.M., Johnston, C.M., Newall, A.E., Formstone, E.J., Arkell, R.M., Nesterova, T.B., Alghisi, G.C., Rastan, S., and Brockdorff, N. 1997. Stabilization of Xist RNA mediates initiation of $\mathrm{X}$ chromosome inactivation. Cell 91: 99-107.

Stavropoulos, N., Lu, N., and Lee, J.T. 2001. A functional role for Tsix transcription in blocking Xist RNA accumulation but not in X-chromosome choice. Proc. Natl. Acad. Sci. 98: 10232-10237.

Stavropoulos, N., Rowntree, R.K., and Lee, J.T. 2005. Identification of developmentally specific enhancers for Tsix in the regulation of X chromosome inactivation. Mol. Cell. Biol. 25: 2757-2769.

Sun, B.K., Deaton, A.M., and Lee, J.T. 2006. A transient heterochromatic state in Xist preempts $\mathrm{X}$ inactivation choice without RNA stabilization. Mol. Cell 21: 617-628.

Turner, B.M. 2002. Cellular memory and the histone code. Cell 111:
285-291.

Umlauf, D., Goto, Y., Cao, R., Cerqueira, F., Wagschal, A., Zhang, Y., and Feil, R. 2004. Imprinting along the Kcnq1 domain on mouse chromosome 7 involves repressive histone methylation and recruitment of Polycomb group complexes. Nat. Genet. 36: 1296-1300.

Vakoc, C.R., Mandat, S.A., Olenchock, B.A., and Blobel, G.A. 2005. Histone $\mathrm{H} 3$ lysine 9 methylation and $\mathrm{HP} 1 \gamma$ are associated with transcription elongation through mammalian chromatin. Mol. Cell 19: 381391.

Vigneau, S., Augui, S., Navarro, P., Avner, P., and Clerc, P. 2006. An essential role for the DXPas34 tandem repeat and Tsix transcription in the counting process of X-chromosome inactivation. Proc. Natl. Acad. Sci. 103: 7390-7395.

Weber, M., Davies, J.J., Wittig, D., Oakeley, E.J., Haase, M., Lam, W.L. and Schubeler, D. 2005. Chromosome-wide and promoter-specific analyses identify sites of differential DNA methylation in normal and transformed human cells. Nat. Genet. 37: 853-862. 


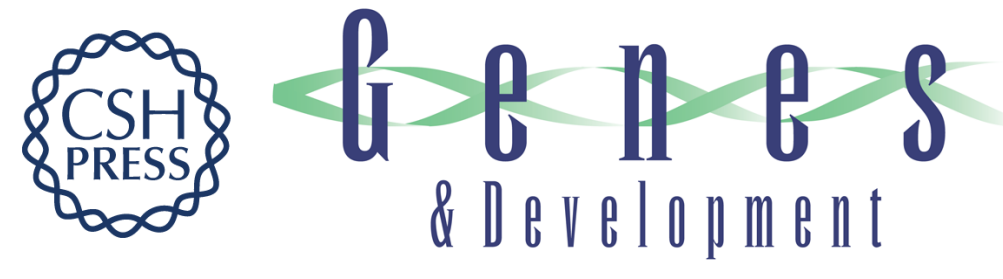

\section{Tsix-mediated epigenetic switch of a CTCF-flanked region of the Xist promoter determines the Xist transcription program}

Pablo Navarro, Damian R. Page, Philip Avner, et al.

Genes Dev. 2006, 20:

Access the most recent version at doi:10.1101/gad.389006

Supplemental http://genesdev.cshlp.org/content/suppl/2006/10/04/20.20.2787.DC1
Material

References This article cites 35 articles, 11 of which can be accessed free at:

http://genesdev.cshlp.org/content/20/20/2787.full.html\#ref-list-1

License

Email Alerting

Receive free email alerts when new articles cite this article - sign up in the box at the top

Service

right corner of the article or click here.

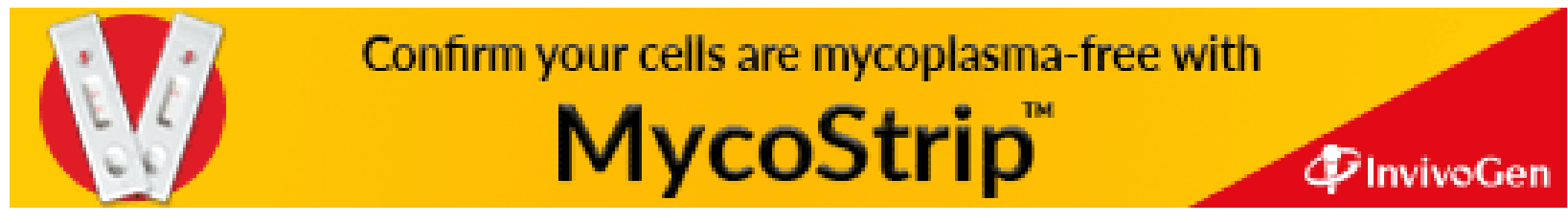

